\title{
The impact of improving feelings of relatedness on motivation and engagement for tertiary students
}

\author{
Ananthan Ambikairajah, R. Ambikairajah \& Eliathamby Ambikairajah
}

To cite this article: Ananthan Ambikairajah, R. Ambikairajah \& Eliathamby Ambikairajah (2019):

The impact of improving feelings of relatedness on motivation and engagement for tertiary students, International Journal of Mathematical Education in Science and Technology, DOI: 10.1080/0020739X.2019.1703149

To link to this article: https://doi.org/10.1080/0020739X.2019.1703149

View supplementary material $\asymp$

曲 Published online: 26 Dec 2019.

Submit your article to this journal $\pi$

Џ Article views: 46

Q View related articles ¿

View Crossmark data $₫$ 


\title{
The impact of improving feelings of relatedness on motivation and engagement for tertiary students
}

\author{
Ananthan Ambikairajah (1) ${ }^{a}$, R. Ambikairajah ${ }^{b}$ and Eliathamby Ambikairajah $\mathbb{A D}^{\mathrm{b}}$ \\ ${ }^{a}$ Centre for Research on Ageing, Health and Wellbeing, Research School of Population Health, Australian

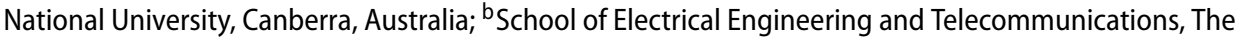 \\ University of New South Wales, Sydney, Australia
}

\begin{abstract}
First-year undergraduates may be particularly prone to experiencing difficulties with facilitating feelings of relatedness, due to the recent shift in educational environments (i.e. from high school to university), which may be unfamiliar. Therefore, the current study aimed to determine whether the implementation of a single pedagogical strategy, centred within the self-determination theory framework, could effectively address students' innate need for relatedness. Specifically, informal verbal feedback was utilized to enhance teacher-student communication, where the teacher spoke with each undergraduate student individually at the start of every lesson for 1-2 minutes. A total of 243 Advanced Science undergraduates enrolled in the first-year course at the University of New South Wales, Sydney, were included in the study. Seventy-one undergraduates were enrolled in 2016, whereas 172 undergraduates were enrolled in 2017. A mixed research methodology was employed to best leverage the utility of both qualitative and quantitative data. Interestingly, the use of informal verbal feedback as a pedagogical strategy significantly improved the student' perceptions of receiving helpful feedback to aid their learning. These findings are important as they emphasize the utility and effectiveness of implementing one new pedagogical strategy to facilitate student' motivation, by enhancing feelings of relatedness.
\end{abstract}

\section{ARTICLE HISTORY}

Received 6 May 2019

\section{KEYWORDS}

Self-determination theory; relatedness; student perspectives; verbal feedback

\section{Introduction}

One in six domestic students attending a public university in Australia will drop out (Australian Government, 2017). Many factors have been implicated; however, poor motivation may be particularly relevant, given that enhanced intrinsic motivation predicts cognitive engagement (Walker, Greene, \& Mansell, 2006), which has a significant effect on student achievement (Hattie, 2008). Therefore, the impact of pedagogical strategies

CONTACT Ananthan Ambikairajah ananthan.ambikairajah@anu.edu.au; a.ambikairajah@gmail.com $\theta$ Centre for Research on Ageing, Health and Wellbeing, Research School of Population Health, Australian National University, Florey, Building 54, Mills Road, Canberra, ACT 2601, Australia

(4) Supplemental data for this article can be accessed at doi:10.1080/0020739X.2019.1703149 
that focus on improving student motivation and engagement to facilitate positive learning experiences requires further investigation.

Self-determination theory (SDT) provides a useful framework for designing pedagogical strategies that address the relationship between motivation and engagement. SDT posits that the satisfaction of innate psychological needs for autonomy, competence and relatedness can positively impact intrinsic motivation (Ryan \& Deci, 2000). Briefly, within an educational setting, autonomy refers to feelings of choice and control of behaviours and goals; relatedness reflects feelings of connectedness, belonging and acceptance, whereas competence involves feelings appropriately challenged to experience mastery (Ryan \& Deci, 2000). Previous research has demonstrated that pedagogy designed to satisfy these needs can promote students' interests, quality of learning, value of education and confidence in their abilities (Deci, Vallerand, Pelletier, \& Ryan, 1991). Therefore, SDT may be particularly useful in addressing the needs of tertiary students.

In practice, instructional style is a critical component of teaching that can impact engagement and learning (Reeve, Jang, Carrell, Jeon, \& Barch, 2004). SDT suggests that a style, which is autonomy-supportive and instills a level of control and independent choice for students, is optimal (Reeve, Jang, Hardre, \& Omura, 2002; Ryan \& Deci, 2000). Jang, Reeve, and Deci (2010) investigated specific features of instructional style that impacted students' engagement and learning. Notably, students provided with an autonomy-supportive environment, which focused on their interests, needs, preferences and personal goals, positively predicted engagement in the classroom. This is further supported by Stefanou, Perencevich, DiCintio, and Turner (2004) who argued that promoting student choice, thereby increasing a student's sense of autonomy, can encourage engagement with the learning activities and also fosters a deeper level of thinking about the subject matter. The importance of this is further echoed by Reeve (2002), who noted that the educational benefits of an autonomy-supportive teacher include an increase in students' academic achievement, perceived competence, self-esteem, and creativity. The evidence, therefore, suggests that a mathematics teacher, who is responsive to student needs and values student choice for mode of learning, would demonstrate an autonomy-focused style of teaching, thereby facilitating engagement, which can predict intrinsic motivation. It is important to note, however, that merely offering choice is not, in itself, a motivating factor, as Evans and Boucher (2015) demonstrated that for choice to be motivating, it needs to be relevant, meaningful and competence-enhancing.

Importantly, it should be acknowledged that it is not always possible for teachers to motivate students intrinsically to complete a task, despite providing autonomy support, due to the nature of the content (Ryan \& Deci, 2000). Reeve et al. (2002) investigated motivational strategies that could support a student's ability to personally endorse and value the effort that they are putting into an uninteresting activity. The motivational strategy, which emerged as useful for engaging students in an uninteresting activity, involved providing a meaningful rationale to students in an autonomy-supportive way. Notably, students reported that teachers who provided a meaningful rationale, promoted feelings of identification with the task's personal value. This suggests that the effective use of this strategy may assist the transition of extrinsically motivated behaviours in becoming intrinsic and self-determined. Previous research supports this assertion, with the evidence that providing a meaningful rationale for an uninteresting behaviour, in conjunction with support for autonomy and relatedness, promotes feelings of internalization and integration 
(Deci, Eghrari, Patrick, \& Leone, 1994). Ultimately, providing rationale emphasizes and brings meaning to the intrinsic value of the task for the student, which promotes meaningful cognitive engagement, thereby providing ideal opportunities for student learning (Reeve, 2013; Walker et al., 2006).

While it has been highlighted how SDT can be incorporated into pedagogical practice, academic staff with insufficient time, resources or support may not be able to effectively modify their pedagogy to address students' needs for autonomy, competence and relatedness holistically. Therefore, a considered yet balanced approach that accounts for factors, such as feasibility and efficacy for implementing SDT-centred pedagogical strategies within a tertiary setting is required to address the learning needs of students and also establish attainable goals for academic staff.

First-year undergraduates may be particularly prone to experiencing difficulties with facilitating feelings of relatedness, due to the recent shift in educational environments (i.e. from high school to university), which may be unfamiliar. First-year courses are typically filled with a large number of students studying different degrees, resulting in less consistent peer interactions across subjects, compared with high-school courses. Interestingly, strategies that promote learning communities by enhancing relatedness between peers and faculty (Reeve \& Halusic, 2009) have been shown to predict student efforts, motivation and academic outcomes significantly (Beachboard, Beachboard, Li, \& Adkison, 2011). Therefore, the current paper aimed to determine whether the implementation of a single pedagogical strategy, centred within the SDT framework, could effectively address students' innate need for relatedness. Specifically, informal verbal feedback was utilized to enhance teacher-student communication, given that the 2016 student's evaluative surveys identified feedback as a key priority area for possible improvement. As improved feelings of relatedness were the desired outcome, informal verbal feedback involved the teacher speaking with each student at the start of every lesson for 1-2 minutes about their progress at the university.

\section{Methods}

\subsection{Participants}

A total of 243 Undergraduate Advanced Science students who were enrolled in the firstyear course at the University of New South Wales, Sydney, were included in the study. The entrance score (i.e. The Australian Tertiary Admission Rank - ATAR) for an Advanced Science degree is 95. Seventy-one undergraduates were enrolled in 2016, whereas 172 undergraduates were enrolled in 2017. The same teacher (AA) taught both 2016 and 2017 cohorts.

\subsection{Measures}

The current study utilized a mixed research methodology with a triangulation design that leveraged the use of both quantitative and qualitative survey data. Specifically, course evaluations (CATEI and MyExperience) were utilized to assess whether the teacher-student communication improved through enhanced verbal feedback. These evaluative tools included Likert-scale questions and an open response section. Likert-scale questions were 
Table 1. Survey questions.

\begin{tabular}{|c|c|}
\hline $\begin{array}{l}\text { Likert-Scale Questions (Quantitative) } \\
2016\end{array}$ & 2017 \\
\hline $\begin{array}{l}\text { 'The facilitator/tutor encouraged student participation } \\
\text { and group discussion' }\end{array}$ & 'Ananthan Ambikairajah encouraged student participation' \\
\hline $\begin{array}{l}\text { 'The facilitator/tutor provided helpful feedback to help } \\
\text { me learn' }\end{array}$ & 'Ananthan Ambikairajah provided helpful feedback' \\
\hline 'The lecturer/tutor is enthusiastic about teaching' & 'Ananthan Ambikairajah was enthusiastic about teaching' \\
\hline $\begin{array}{l}\text { 'Overall, I was satisfied with the quality of this } \\
\text { facilitator's/tutor's teaching' }\end{array}$ & $\begin{array}{l}\text { 'Overall I was satisfied with the quality of Ananthan } \\
\text { Ambikairajah's teaching' }\end{array}$ \\
\hline \multicolumn{2}{|l|}{ Open Response Questions (Qualitative) } \\
\hline $\begin{array}{l}\text { 'The best features of this facilitator's/tutor's teaching } \\
\text { were' }\end{array}$ & $\begin{array}{l}\text { 'The best features of Ananthan Ambikairajah's teaching } \\
\text { were' }\end{array}$ \\
\hline $\begin{array}{l}\text { 'This facilitator's/tutor's teaching in this course could } \\
\text { be improved by' }\end{array}$ & 'Ananthan Ambikairajah's teaching could be improved by' \\
\hline
\end{tabular}

assigned values on a 6-point scale: $1=$ Strongly Disagree; $2=$ Disagree; $3=$ Mildly Disagree; $4=$ Mildly Agree; $5=$ Agree; $6=$ Strongly Agree. Questions that were asked in both 2016 and 2017 have been included in Table 1.

\subsection{Statistical analyses}

All statistical analyses were conducted using the open-source software, $\mathrm{R}$ (version 3.3.3) ( $\mathrm{R}$ Core Team, 2017), running in RStudio (version 1.0.143) (RStudio Team, 2015). Given the debate regarding the appropriate statistical test for analysing the Likert-scale data used in surveys (Norman, 2010), we have employed both parametric (i.e. Student's t-test) and nonparametric (i.e. Mann-Whitney's U-test) approaches. Importantly, mean scores have also been provided so that $p$-values can be interpreted concerning their corresponding effect sizes (i.e. the difference between means).

\subsection{Intervention strategy}

Each lesson was scheduled for $2 \mathrm{~h}$. At the beginning of each lesson (across a 13-week semester), the teacher would spend approximately 1-2 minutes with each student, circulating around the classroom for each interaction. Depending on class sizes, these interactions would take approximately 30 minutes to complete for the entire class. As such, 30 minutes was allocated for feedback focused teacher-student interactions, whereas the remaining 90 minutes were dedicated to coursework-related pedagogy.

In these interactions the teacher would provide the student with informal verbal feedback about their progress in the course and ask questions to determine how the student was coping with the university. Example questions included:

- How are you going in your other subjects?

- Do you feel like you are coping well with the university?

- Have you been able to meet other students in your classes?

- What assessments do you have coming up?

- Are you prepared for your assessments?

- What possible strategies could help you between now and next week? 
These core questions provided the foundation for most interactions, with each conversation developing organically from these stimulus points. Wherever possible, the teacher sought to help the student seek meaning in their studies and/or current challenges. As the weeks progressed, the teacher would learn more about the students', which resulted in richer interactions.

\section{Results}

\subsection{Quantitative results}

In 2016, 65 out of 71 students (91.55\%) completed the course evaluative survey, compared to 166 out of 172 students (96.51\%) in 2017, reflecting an increase in the response rate despite the larger number of students.

For the Likert-scale questions including 'The facilitator/tutor encouraged student participation and group discussion', 'The facilitator/tutor is enthusiastic about teaching' and 'Overall, I was satisfied with the quality of this facilitator's/tutor's teaching', there was no significant difference between 2016 and 2017 cohorts (Tables 2-4). However, for the Likertscale question 'The facilitator/tutor provided helpful feedback to help me learn', there was a significant increase in the mean score (Table 5). All quantitative responses from 2016 and 2017 have been included in the supplementary materials.

\subsection{Qualitative results}

The 2016 open response questions included statements as

Enthusiastic, motivated and engaging

Energetic, passionate, interesting and motivational

Table 2. The facilitator/tutor encouraged student participation and group discussion.

\begin{tabular}{lcccr}
\hline & N & Mean Score (out of 6) & Mann-Whitney U Test & T-Test \\
\hline S1, 2016 & 71 & 5.8769 & & \\
S1, 2017 & 166 & 5.8434 & 0.8396 & 0.6352
\end{tabular}

Note: $\mathrm{n}=$ number of responses.

a 2017 Question was amended to: 'Ananthan Ambikairajah encouraged student participation'.

Table 3. The lecturer/tutor is enthusiastic about teaching.

\begin{tabular}{lcccr}
\hline & $\mathrm{n}$ & Mean Score (out of 6) & Mann-Whitney U Test & T-Test \\
\hline S1, 2016 & 71 & 5.9692 & & \\
S1, 2017 & 165 & 5.9455 & 0.9941 & 0.5425 \\
\hline
\end{tabular}

Note: $\mathrm{n}=$ number of responses.

a2017 Question was amended to: 'Ananthan Ambikairajah was enthusiastic about teaching'

Table 4. Overall, I was satisfied with the quality of this facilitator's/tutor's teaching.

\begin{tabular}{lcccr}
\hline & $\mathrm{n}$ & Mean Score (out of 6) & Mann-Whitney U Test & T-Test \\
\hline $\mathrm{S} 1,2016$ & 71 & 5.8923 & & \\
$\mathrm{~S} 1,2017^{\mathrm{a}}$ & 163 & 5.8834 & .3280 & 0.8834 \\
\hline
\end{tabular}

Note: $\mathrm{n}=$ number of responses.

a2017 Question was amended to: 'Overall I was satisfied with the quality of Ananthan Ambikairajah's teaching'. 
Table 5. The facilitator/tutor provided helpful feedback to help me learn.

\begin{tabular}{lcccr}
\hline & $\mathrm{n}$ & Mean Score (out of 6) & Mann-Whitney U Test & T-Test \\
\hline $\mathrm{S} 1,2016$ & 71 & 5.5077 & & \\
$\mathrm{~S} 1,2017^{\mathrm{a}}$ & 162 & 5.7099 & 0.0048 & 0.0341 \\
\hline
\end{tabular}

Note: $\mathrm{n}=$ number of responses.

a 2017 Question was amended to: 'Ananthan Ambikairajah provided helpful feedback'.

Comparatively, the 2017 open response questions included more statements that reflected themes, which focused on the impact that the teacher had on student feelings of relatedness, such as

He really engaged with EVERY student in our tutorial and I'm sure he did for EVERY class he teaches

The connection with the students. He made everyone feel valued in his classroom

He would talk to his students before class-strongly decreases the distance between teacher and student

He made sure to check up on every student before class started and this made for a really comfortable teaching space

Mr. Ambi's enthusiasm for forming friendships with and between us made the tutorials much more enjoyable and engaging than any others undertook

All qualitative responses from 2016 and 2017 have been included in the supplementary materials.

\section{Discussion}

This study investigated whether the implementation of a single pedagogical strategy, centred within the SDT framework, could effectively address students' innate need for relatedness. Specifically, informal verbal feedback was utilized to enhance teacher-student communication, which involved the teacher speaking with each student at the start of every lesson for 1-2 minutes to discuss their progress in the university. The topic of conversation with students followed similar themes, including (1) how the student was progressing in the current class, (2) how the student was coping, more broadly, with his/her other university subjects with regard to assignments or upcoming exams and (3) how the student was coping with the transition from high school to a university environment.

Interestingly, the use of informal verbal feedback as a pedagogical strategy significantly improved student perceptions of receiving helpful feedback to help student learning. Taken together with the qualitative results, these findings indicate that the use of informal feedback can enhance student feelings of relatedness and support their engagement and motivation for learning within the classroom. Furthermore, informal verbal feedback did not significantly change student perceptions about the enthusiasm of the teacher, the quality of the teaching and the encouragement for student participation. Given that the baseline score was already high, with the lowest score being 5.88 (out of 6), these results indicate that it was not detrimental to student perceptions of the quality of the course when informal verbal feedback was incorporated into pedagogy.

Notably, the response rate (i.e. students enrolled in the course who completed the survey divided by the entire cohort of students) was not only very high but also increased across years (from $91.55 \%$ in 2016 to $96.51 \%$ in 2017). These results are surprising given that the sample size increased significantly across years (from 71 to 172 students). It is possible that 
the implementation of the pedagogical strategy for informal feedback had the unintended consequence of improving student motivation for completing the survey. This could be because the students appreciated the use of informal feedback and used the survey as an opportunity to voice their encouragement of the pedagogical strategy so that it was retained for future cohorts.

Previous research has highlighted the importance of a wide range of pedagogical strategies to enhance student motivation in the classroom (Niemiec \& Ryan, 2009). For example, the flipped classroom model can facilitate feelings of relatedness by encouraging collaborative peer-to-peer practice while developing critical thinking and problem-solving skills (Zainuddin \& Perera, 2017). Furthermore, teachers, who engage in relatedness supportive pedagogical practice, benefit and have reported higher levels of work engagement and enjoyment, in addition to lower levels of anxiety, anger and emotional exhaustion (Klassen, Perry, \& Frenzel, 2012). Taken together, these findings emphasize the importance of incorporating an SDT framework within the pedagogical practice. However, the current study is unique in its ability to recognize that academic teaching staff may lack the sufficient time, resources or support to modify their pedagogy to address all facets of SDT holistically. While strategies, such as the flipped classroom, have demonstrated their effectiveness and utility in fostering student feelings of relatedness and overall motivation, the implementation of such strategies may not be possible to implement for all academic teaching staff. The current study offers a considered yet balanced approach that accounts for factors, such as feasibility and efficacy for implementing SDT-centred pedagogical strategies within a tertiary setting, to address the learning needs of students and also establish attainable goals for academic staff. These findings also emphasize that effective pedagogical strategies for enhancing relatedness within an SDT framework include those that convey warmth, care and respect towards students, in addition to fostering student feelings that the teacher genuinely likes, values and respects them (Niemiec \& Ryan, 2009).

\subsection{Teacher observations}

Observationally, it was evident that voluntary student classroom participation was higher in 2017 than in 2016. While there are many possible reasons for this, including varying cohort effects and class sizes, it is important to note that the inclusion of student's voice through informal verbal feedback may have beneficially impacted how students interacted in the classroom. Consequentially, the quality of class discussions improved because more students were providing their input resulting in a greater diversity of thoughts, ideas and opinions.

While the admission score for the Advanced Science degree was relatively high $($ ATAR $=95)$ there was still a wide distribution of abilities and motivational levels among undergraduates. There are many possible reasons for this, including the difference in the demands of the curriculum between high school and universities. As a result, undergraduates that are unable to adapt to the rigorous learning requirements of the tertiary education, tend to struggle. Furthermore, the lack of structured support and guidance in the university, compared to high school, may result in feelings of amotivation within some students. First-year undergraduates may be particularly prone to this, given that they have not had an opportunity to acclimatize appropriately to a tertiary environment. Evidently, a high entrance score likely reflects the performance of students in a high school environment and 
may not necessarily predict the ability and motivation levels of undergraduates. Therefore, the first-year undergraduates included in the current study were well suited for a targeted pedagogical strategy that focused on enhancing motivation and engagement.

Interestingly, students still came to class early, even though the first 30 minutes were dedicated to the pedagogical strategy of informal verbal feedback. In addition to the quantitative results, these observations suggest that the students enjoyed the personalized interactions, which facilitated a positive learning environment. Additionally, during the start of the lesson when the teacher was moving around the room speaking with individual students, the remainder of the class utilized the opportunity to have conversations with one another and form meaningful connections, which fostered feelings of relatedness.

\subsection{Strengths and limitations}

A key strength of this study was that the same teacher taught the students across both years (2016 and 2017), which enabled the implementation of a strategic pedagogical intervention to improve student feelings of relatedness to be measured across cohorts. Therefore, the 2016 cohort acted as a control group for the 2017 cohort, which enabled clear comparisons to be made between groups. Furthermore, the current study has leveraged the use of both quantitative and qualitative data to ensure that a holistic interpretation of results could be achieved. Finally, the high response rate from students across years is a notable strength of this study, which minimized nonresponse bias and provided more confidence that the results represent the views and opinions of the entire cohort. Limitations of this study include possible confounding variables that could not be controlled for between years, including class sizes, the total number of enrolled students and a different cohort of students.

\section{Conclusion}

The key findings of this study revealed that the use of informal verbal feedback improves student perceptions of receiving helpful feedback to help students' learning, thereby facilitating feelings of relatedness. The use of relatedness supporting pedagogical strategies may improve student response rate on questionnaires because students have improved levels of motivation and engagement in the classroom. These findings are important as they emphasize the utility and effectiveness of implementing one new pedagogical strategy to facilitate student motivation, by enhancing feelings of relatedness. Future studies would benefit from utilizing a longitudinal design to determine the effects that relatedness supportive strategies can have on student learning outcomes.

\section{Acknowledgements}

We thank all the students who were part of the study. We also acknowledge the University of New South Wales, Sydney, who were responsible for the CATEI and MyExperience survey tools that were used in this study.

\section{Disclosure statement}

No potential conflict of interest was reported by the authors. 


\section{Funding}

No funding was sought to conduct this research.

\section{Data availability statement}

All data can be found in the supplementary materials.

\section{ORCID}

Ananthan Ambikairajah (D) http://orcid.org/0000-0002-5808-8020

Eliathamby Ambikairajah (iD http://orcid.org/0000-0003-4673-6534

\section{References}

Australian Government. (2017). Attrition, success and retention. Retrieved from https://docs. education.gov.au/documents/2017-section-15-attrition-success-and-retention

Beachboard, M. R., Beachboard, J. C., Li, W., \& Adkison, S. R. (2011). Cohorts and relatedness: Self-determination theory as an explanation of how learning communities affect educational outcomes. Research in Higher Education, 52(8), 853-874.

Deci, E. L., Eghrari, H., Patrick, B. C., \& Leone, D. R. (1994). Facilitating internalization: The selfdetermination theory perspective. Journal of Personality, 62(1), 119-142.

Deci, E. L., Vallerand, R. J., Pelletier, L. G., \& Ryan, R. M. (1991). Motivation and education: The self-determination perspective. Educational Psychologist, 26(3-4), 325-346.

Evans, M., \& Boucher, A. R. (2015). Optimizing the power of choice: Supporting student autonomy to foster motivation and engagement in learning. Mind, Brain, and Education, 9(2), 87-91.

Hattie, J. (2008). Visible learning: A synthesis of over 800 meta-analyses relating to achievement. Abingdon, Oxon: Routledge.

Jang, H., Reeve, J., \& Deci, E. L. (2010). Engaging students in learning activities: It is not autonomy support or structure but autonomy support and structure. Journal of Educational Psychology, 102(3), 588.

Klassen, R. M., Perry, N. E., \& Frenzel, A. C. (2012). Teachers' relatedness with students: An underemphasized component of teachers' basic psychological needs. Journal of Educational Psychology, 104(1), 150.

Niemiec, C. P., \& Ryan, R. M. (2009). Autonomy, competence, and relatedness in the classroom: Applying self-determination theory to educational practice. Theory and Research in Education, $7(2), 133-144$.

Norman, G. (2010). Likert scales, levels of measurement and the "laws" of statistics. Journal of Advances in Health Sciences Education, 15(5), 625-632.

R Core Team. (2017). R: A language and environment for statistical computing. Vienna: R Foundation for Statistical Computing.

Reeve, J. (2002). Self-determination theory applied to educational settings. In E. L. Deci \& R. M. Ryan (Eds.), Handbook of self-determination research (pp. 183-203). Rochester, NY: University of Rochester Press..

Reeve, J. (2013). How students create motivationally supportive learning environments for themselves: The concept of agentic engagement. Journal of Educational Psychology, 105(3), 579.

Reeve, J., \& Halusic, M. (2009). How K-12 teachers can put self-determination theory principles into practice. Theory and Research in Education, 7(2), 145-154. doi:10.1177/1477878509104319

Reeve, J., Jang, H., Carrell, D., Jeon, S., \& Barch, J. (2004). Enhancing students' engagement by increasing teachers' autonomy support. Motivation and Emotion, 28(2), 147-169. doi:10.1023/B:MOEM.0000032312.95499.6f

Reeve, J., Jang, H., Hardre, P., \& Omura, M. (2002). Providing a rationale in an autonomy-supportive way as a strategy to motivate others during an uninteresting activity. Motivation and Emotion, 26(3), 183-207. doi:10.1023/a:1021711629417 
RStudio Team. (2015). RStudio: Integrated development for R. Boston, MA: RStudio. Retrieved from http://www.rstudio.com, 42

Ryan, R. M., \& Deci, E. L. (2000). Self-determination theory and the facilitation of intrinsic motivation, social development, and well-being. American Psychologist, 55(1), 68.

Stefanou, C. R., Perencevich, K. C., DiCintio, M., \& Turner, J. C. (2004). Supporting autonomy in the classroom: Ways teachers encourage student decision making and ownership. Educational Psychologist, 39(2), 97-110.

Walker, C. O., Greene, B. A., \& Mansell, R. A. (2006). Identification with academics, intrinsic/extrinsic motivation, and self-efficacy as predictors of cognitive engagement. Learning and Individual Differences, 16(1), 1-12. doi:10.1016/j.lindif.2005.06.004

Zainuddin, Z., \& Perera, C. J. (2017). Exploring students' competence, autonomy and relatedness in the flipped classroom pedagogical model. Journal of Further and Higher Education, 43(1), 115-126. doi:10.1080/0309877X.2017.1356916 